University of Nebraska - Lincoln

DigitalCommons@University of Nebraska - Lincoln

Calculus-Based General Physics

Instructional Materials in Physics and

Astronomy

1975

EQUILIBRIUM OF RIGID BODIES

Follow this and additional works at: https://digitalcommons.unl.edu/calculusbasedphysics

Part of the Other Physics Commons

"EQUILIBRIUM OF RIGID BODIES" (1975). Calculus-Based General Physics. 13.

https://digitalcommons.unl.edu/calculusbasedphysics/13

This Article is brought to you for free and open access by the Instructional Materials in Physics and Astronomy at DigitalCommons@University of Nebraska - Lincoln. It has been accepted for inclusion in Calculus-Based General Physics by an authorized administrator of DigitalCommons@University of Nebraska - Lincoln. 
Module

STUDY GUIDE

\section{EQUILIBRIUM OF RIGID BODIES}

INTRODUCTION

Most of the objects that one sees are in a state of equilibrium, that is, at rest or in a state of uniform motion. Many man-made structures are designed to achieve and sustain a state of equilibrium, and this, in turn, sets requirements to the materials (their sizes and shapes) that can be used. This module will give you some practice in analyzing the forces that result in equilibrium. From this analysis, if you are given the values of an appropriate set of forces you can find the remaining ones. On the other hand, in designing a stable system you can find the requirements of materials and dimensions that will ensure equilibrium.

\section{PREREQUISITES}

Before you begin this module, you should be able to:

*Apply Newton's second law for the solution of problems involving frictional forces (needed for Objectives 2 and 3 of this module)

* Locate the center of mass of a uniform rigid body (needed for Objective 1 of this module)

*Define and use the definition of torque (needed for Objectives 1 and 3 of this module)
Location of Prerequisite Content

Newtons Laws Module

Impulse and Momentum Module

Rotational Motion Module

\section{LEARNING OBJECTIVES}

After you have mastered the content of this module, you will be able to:

1. Equilibrium - Define the following terms and describe the application of each to a physical object or system: first condition of equilibrium (translational); second condition of equilibrium (rotational); center of gravity.

2. Translational equilibrium - Analyze translational equilibrium problems by identifying all forces, making a free-body diagram, and applying the first condition of equilibrium to solve for the unknown parameters. These problems may involve weight acting at the center of gravity, tensions in ropes or wires, compressional forces on rods or hinges, and frictional forces. 
3. Rotational equilibrium - Analyze problems involving both the first and second conditions of equilibrium. These problems will involve torques as well as the forces referred to in objective 2.

\section{GENERAL COMMENTS}

The solutions to the problems of this module are rather formal; that is, all problem solutions follow a regular procedure, which if done carefully will almost always produce the desired result. By Tearning the general procedures and practicing on a few examples you should find no difficulty in solving any problem in this module.

Since your text may not delineate these steps clearly, they are summarized here:

1. Draw an imaginary boundary separating the system under consideration from its surroundings.

2. Draw vectors representing magnitude, direction, and point of application of all external forces to the system. (This is a free-body diagram.)

3. Choose a convenient reference frame, resolve all of the external forces along these axes, and then apply the first condition of equilibrium.

4. Choose a convenient axis, evaluate all of the external torques around it, and apply the second condition of equilibrium.

The resulting simultaneous equations can then be solved for the desired quantities. 
TEXT: Frederick J. Bueche, Introduction to Physics for Scientists and Engineers (McGraw-Hi11, New York, 1975), second edition

\section{SUGGESTED STUDY PROCEDURE}

Study the text Sections 3.1 through 3.4 in Chapter 3 and Section 11.9 in Chapter 11. Next study the Problem Set in this module, and work text problems, remembering to use the rules given in General Comments, until you are satisfied that you have met objectives 1 to 3 .

Try the Practice Test before attempting a Mastery Test.

$$
\text { BUECHE }
$$

\begin{tabular}{|c|c|c|c|c|c|c|}
\hline \multirow[t]{2}{*}{$\begin{array}{l}\text { Objective } \\
\text { Number }\end{array}$} & \multirow[t]{2}{*}{ Readings } & \multicolumn{2}{|c|}{$\begin{array}{l}\text { Problems with } \\
\text { Solutions } \\
\end{array}$} & \multicolumn{2}{|c|}{ Assigned Problems } & \multirow{2}{*}{$\begin{array}{l}\text { Additional } \\
\text { Problems } \\
\text { (Chap. 3) }\end{array}$} \\
\hline & & $\begin{array}{l}\text { Study } \\
\text { Guide }\end{array}$ & Text* & $\begin{array}{l}\text { Study } \\
\text { Guide }\end{array}$ & $\begin{array}{l}\text { Text } \\
\text { (Chap. 3) }\end{array}$ & \\
\hline 1 & $\begin{array}{c}\operatorname{Secs}, 3.1 \\
3.2 \\
3.4,11.9\end{array}$ & & & & & \\
\hline 2 & Sec. 3.1 & $A, B$ & $\begin{array}{l}\text { I11us. } \\
3.1 \text { to } \\
3.3\end{array}$ & $E$ & $\begin{array}{l}3-5,8 \\
10\end{array}$ & $\frac{1}{9}, 2,6,7$, \\
\hline 3 & Sec. 3.2 & $C, D$ & $\begin{array}{l}\text { I11us. } \\
3.4 \text { to } \\
3.7\end{array}$ & $\mathrm{~F}$ & $18-21$ & $22-25$ \\
\hline
\end{tabular}

*I11us. = I1lustration(s). 
TEXT: David Halliday and Robert Resnick, Fundamentals of Physics (Wiley, New York, 1970; revised printing, 1974)

SUGGESTED STUDY PROCEDURE

Study text Sections 12-1 through 12-3 in Chapter 12. Then study the Problem Set in this module, remembering to use the rules given in General Comments. Work text problems until you are satisfied that you have met objectives 1 to 3 .

Try the Practice Test before attempting a Mastery Test.

HALLIDAY AND RESNICK

\begin{tabular}{|c|c|c|c|c|c|c|}
\hline \multirow[t]{2}{*}{$\begin{array}{l}\text { Objective } \\
\text { Number }\end{array}$} & \multirow[t]{2}{*}{ Readings } & \multicolumn{2}{|c|}{$\begin{array}{l}\text { Problems with } \\
\text { Solutions }\end{array}$} & \multicolumn{2}{|c|}{ Assigned Problems } & \multirow{2}{*}{$\begin{array}{l}\text { Additional } \\
\text { Problems } \\
\text { (Chap. 12) }\end{array}$} \\
\hline & & $\begin{array}{l}\text { Study } \\
\text { Guide }\end{array}$ & Text* & $\begin{array}{l}\text { Study } \\
\text { Guide }\end{array}$ & $\begin{array}{c}\text { Text } \\
\text { (Chap. 12) }\end{array}$ & \\
\hline 1 & $\begin{array}{l}\text { Secs. } 12-1, \\
12-2\end{array}$ & & & & & \\
\hline 2 & Sec. 12-3 & $A, B$ & $\begin{array}{l}\text { Chap. } 5, \\
\text { Ex. 3, } 4\end{array}$ & $E$ & $\begin{array}{l}7,15,22, \\
26\end{array}$ & \\
\hline 3 & Sec. $12-3$ & $C, D$ & $\begin{array}{l}\text { Chap: 12, } \\
\text { Ex. 1, } 2\end{array}$ & $F$ & $\begin{array}{l}6,10,12, \\
20,29\end{array}$ & $\begin{array}{l}8,9,11,13, \\
14,16-21, \\
27-29\end{array}$ \\
\hline
\end{tabular}

*Ex. $=$ Example. 
TEXT: Francis Weston Sears and Mark W. Zemansky, University Physics (AddisonWesley, Reading, Mass., 1970), fourth edition

\section{SUGGESTED STUDY PROCEDURE}

Study the text Sections 2-1 through 2-7 of Chapter 2 and 3-1 through 3-4 of Chapter 3. Note that most of Chapter 2 was covered in your study of Newton's laws. Review it now from the viewpoint of statics.

Study the Problem Set in this module; work Problems $E$ and $F$, remembering to use the rules of General Comments. Work text problems until you are satisfied that you have met objectives 1 to 3 .

Try the Practice Test before attempting a Mastery Test.

SEARS AND ZEMANSKY

\begin{tabular}{|c|c|c|c|c|c|c|}
\hline \multirow[t]{2}{*}{$\begin{array}{l}\text { Objective } \\
\text { Number }\end{array}$} & \multirow[t]{2}{*}{ Readings } & \multicolumn{2}{|c|}{$\begin{array}{l}\text { Problems with } \\
\text { Solutions } \\
\end{array}$} & \multicolumn{2}{|c|}{ Assigned Problems } & \multirow[t]{2}{*}{$\begin{array}{l}\text { Additional } \\
\text { Problems }\end{array}$} \\
\hline & & $\begin{array}{l}\text { Study } \\
\text { Guide }\end{array}$ & Text* & $\begin{array}{l}\text { Study } \\
\text { Guide }\end{array}$ & Text & \\
\hline 1 & $\begin{array}{l}\text { Secs. 2-2, } \\
2-6,3-2 \text {, } \\
3-4\end{array}$ & & & & & \\
\hline 2 & $\begin{array}{l}\text { Secs. 2-6, } \\
2-7\end{array}$ & $A, B$ & $\begin{array}{l}\text { Sec. } \\
2-6, \\
\text { Ex. } 2 \\
\text { to } 5 \text {; } \\
\text { Sec. } \\
2-7, \\
\text { Ex. } 1 \text {, } \\
3,4\end{array}$ & $E$ & $\begin{array}{l}2-9 \\
2-10 \\
2-18 \\
2-21\end{array}$ & $\begin{array}{l}2-3 \text { to } 2-8, \\
2-11,2-12, \\
2-14,2-16, \\
2-19,2-20 \\
2-22 \text { to } 2-25\end{array}$ \\
\hline 3 & $\begin{array}{l}\text { Secs. 3-2, } \\
3-3\end{array}$ & $C, D$ & $\begin{array}{l}\text { Sec. } \\
3-2, \\
\text { Ex. } 1 \\
\text { to } 3\end{array}$ & $F$ & $\begin{array}{l}3-4 \\
3-12 \\
3-17 \\
3-19\end{array}$ & $\begin{array}{l}3-3,3-6 \text { to } \\
3-11,3-13, \\
3-15,3-16 \\
3-18,3-20\end{array}$ \\
\hline
\end{tabular}

${ }^{*}$ Ex. $=$ Example $(s)$. 
TEXT: Richard T. Weidner and Robert L. Sell.s, Elementary Classical Physics (Allyn and Bacon, Boston, 1973), second edition, Vol. I

\section{SUGGESTED STUDY PROCEDURE}

Study the text Sections 12-5 and 12-6 in Chapter 12. A1so review Sections 8-1 and 8-2 of Chapter 8 where equilibrium is treated as a special case of Newton's laws.

Study the Problem Set and work Problems E and F. Work text problems, remembering to use the rules from General Comments, until you are satisfied that you have met Objectives 1 to 3 .

Try the Practice Test before attempting a Mastery Test.

WEIDNER AND SELLS

\begin{tabular}{|c|c|c|c|c|c|c|}
\hline \multirow[t]{2}{*}{$\begin{array}{l}\text { Objective } \\
\text { Number }\end{array}$} & \multirow[t]{2}{*}{ Readings } & \multicolumn{2}{|c|}{$\begin{array}{c}\text { Problems with } \\
\text { Solutions } \\
\end{array}$} & \multicolumn{2}{|c|}{ Assigned Problems } & \multirow[t]{2}{*}{$\begin{array}{l}\text { Additional } \\
\text { Problems }\end{array}$} \\
\hline & & $\begin{array}{l}\text { Study } \\
\text { Guide }\end{array}$ & Text* & $\begin{array}{l}\text { Study } \\
\text { Guide }\end{array}$ & Text & \\
\hline 1 & $\begin{array}{l}\text { Secs. 12-5, } \\
12-6\end{array}$ & & & & & \\
\hline 2 & Sec. 12-6 & $A, B$ & $\begin{array}{l}E x \\
8-2\end{array}$ & $E$ & $\begin{array}{l}8-1 \\
8-2 \\
8-4 \\
8-12\end{array}$ & \\
\hline 3 & Sec. $12-6$ & $C, D$ & $\begin{array}{l}\text { Ex. } \\
12-10\end{array}$ & $\mathrm{~F}$ & $\begin{array}{l}12-31 \\
12-32 \\
12-34 \\
12-35\end{array}$ & $\begin{array}{l}12-29, \\
12-33,12-30\end{array}$ \\
\hline
\end{tabular}

${ }^{E x}$. $=$ Example $(s)$. 


\section{PROBLEM SET WITH SOLUTIONS}

$A(2)$. A block of mass $12.0 \mathrm{~kg}$ slides at constant velocity when pushed by a force of $50 \mathrm{~N}$ applied at $30.0^{\circ}$ as shown in Figure 1 . Find the coefficient of sliding friction between the block and floor.

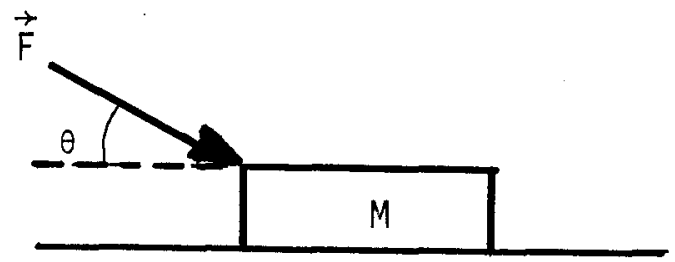

Figure 1

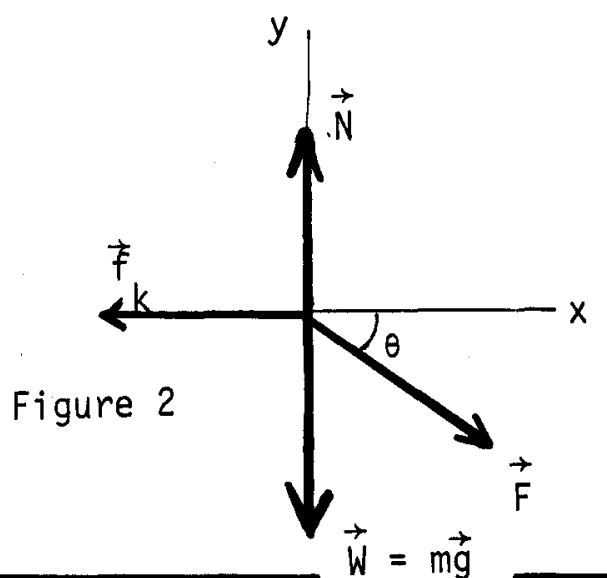

Solution

The expression "at constant velocity" suggests that this is a translational equilibrium problem. First isolate the system, which in this case is just the block M. Then jdentify all forces and draw a free-body diagram showing all forces. See Figure 2: $\vec{W}$ is the weight of the block, $\vec{N}$ is the normal force of the floor on the block, $\vec{F}$ is the applied force, and $\vec{f}_{k}$ is the kinetic frictional force for which we assume $\vec{f}_{k}=\mu_{k} \vec{N}$. Since nothing is said in the problem about the points of application of forces we assume we shall not need to apply the second condition of equilibrium. Thus, applying the first condition of equilibrium:

$$
\Sigma F_{y}=N-W-F \sin \theta=0, \quad \Sigma F_{x}=F \cos \theta-f_{k}=0,
$$

and also $f_{k}=\mu_{k} N$. Note that in this case the normal force $\vec{N}$ is not simply the weight. We can combine the last two equations to eliminate the frictional force:

$$
F \cos \theta-\mu_{k} N=0 \text {. }
$$

This equation can then be combined with the first equation to eliminate the normal force $N$ and we then solve for $\mu_{k}$ :

$N=(F \cos \theta) / \mu_{k}, \quad(F \cos \theta) / \mu_{k}-W-F \sin \theta=0, \quad \mu_{k}=(F \cos \theta) /(W+F \sin \theta)$.

This result is certainly plausible since it is a dimensionless ratio of forces that is expected, and if we let $\theta=0$ it reduces to the defining equation for the coefficient of friction ( $w i$ th $W=N$ ).

Substituting in the numbers from the problem we get the answer

$$
\mu_{k}=(50)\left(\cos 30.0^{\circ}\right) /\left[(12.0)(9.8)+50 \sin 30.0^{\circ}\right]=0.300 \text {. }
$$


$B(2)$. A weight $W$ is hung from the middle of a tight clothesline $20.0 \mathrm{~m}$ long (see Fig. 3). The weight causes the center to drop $0.50 \mathrm{~m}$ below the horizontal (assume the line stretches slightly). Find the tension in the line in terms of $W$.

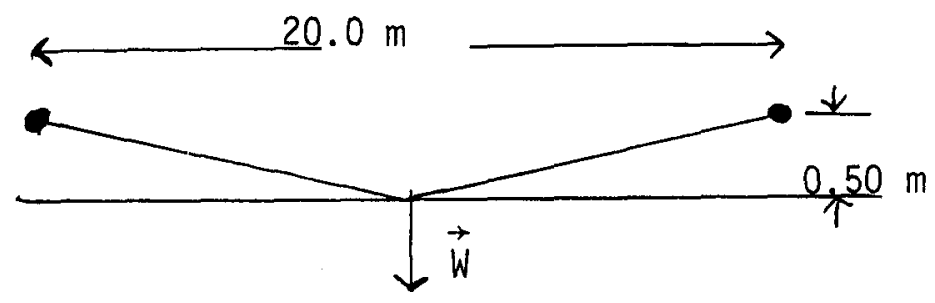

Figure 3

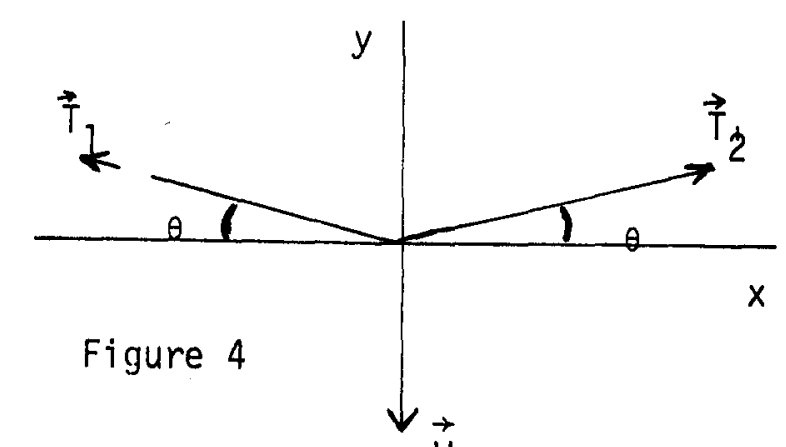

Solution

We assume a first condition of equilibrium and isolate the point of application of $W$ on the line as the object in equilibrium, resulting in Figure 4.

"Clothesline" implies flexibility, which implies that T must be along the "line," and hence the force diagram will have the same angles as the line itself. Thus

$$
\begin{aligned}
& \tan \theta=0.50 / 10.0=0.050 . \\
& \Sigma F_{X}=T_{2} \cos \theta-T_{1} \cos \theta=0,
\end{aligned}
$$

hence,

$$
T_{1}=T_{2}, \quad \Sigma F_{y}=2 T_{1} \sin \theta-W=0, \quad T_{1}=W /(2 \sin \theta)=10.0 W .
$$

$\mathrm{C}(3)$. A uniform beam $5.0 \mathrm{~m}$ long with mass $10.0 \mathrm{~kg}$ is hinged at a wall. The outer end is supported by a guy wire making an angle of $30.0^{\circ}$ with the horizontal beam, and an object of mass $20.0 \mathrm{~kg}$ is hung on the beam at a point $4.5 \mathrm{~m}$ from the wall. See Figure 5 . Find the tension in the guy wire and the vertical and horizontal components of the force on the beam hinge by the wall.
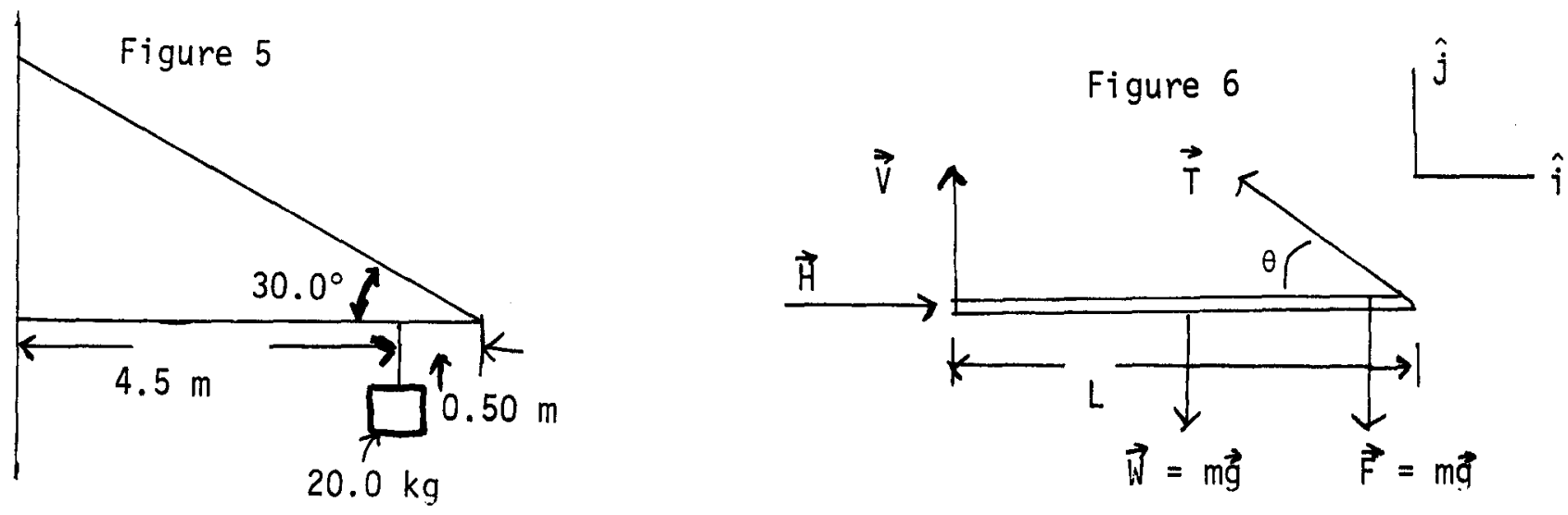


\section{Solution}

For the free-body diagram, see Figure 6 . The first condition of equilibrium results in the following equations:

$$
\Sigma F_{y}=V+T \sin \theta-W-F=0, \quad \Sigma F_{x}=H-T \cos \theta=0 .
$$

The second condition of equilibrium applied to an axis perpendicular to the paper at the hinge gives

$$
\Sigma \tau=T(\sin \theta) L-(W)(L / 2)-F(0.90) L=0 .
$$

Solution of this last equation for $T$ using the values of $L, W, F$, and $\theta$ from the problem gives $T=450 \mathrm{~N}$. The first two equations can then be solved to give

$H=390 \mathrm{~N}, \quad \mathrm{~V}=69 \mathrm{~N}$.

$D(3)$. Physics teachers can be very devious.

One such teacher drilled several holes in an otherwise good wooden meterstick and filled the holes with lead. He then gave the meterstick, a knife edge, and a hanging $0.100-\mathrm{kg}$ mass to a student and asked him to find the mass and center of gravity of the modified meterstick. The student found that the stick balanced at $0.58 \mathrm{~m}$ with the hanging mass at $0.66 \mathrm{~m}$ and also balanced at $0.73 \mathrm{~m}$ with the

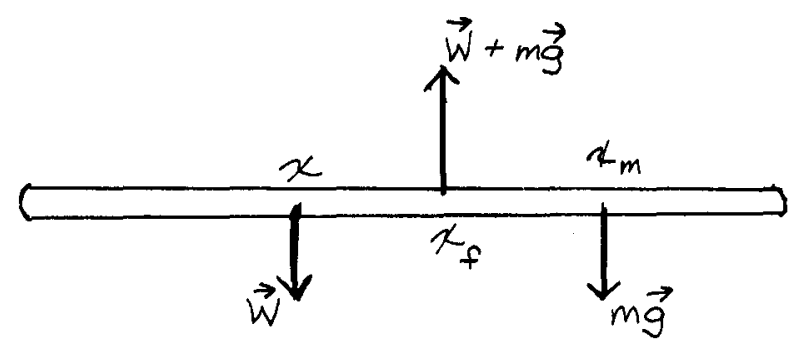
hanging mass at $0.93 \mathrm{~m}$. Find the mass and the center of gravity.

\section{Solution}

Assume the meterstick weight $W$ to act at $X$ and write two equations for $\Sigma \tau=0$ around the 0.0 end. The upward force at the knife edge can be found from the first condition of equilibrium:

$$
\begin{aligned}
& {[W+(0.100)(9.8)](0.58)-W X-(0.100)(9.8)(0.66)=0,} \\
& {[W+(0.100)(9.8)](0.73)-W X-(0.100)(9.8)(0.93)=0 .}
\end{aligned}
$$

Simultaneous solution of these equations gives

$$
X=0.48 \mathrm{~m}, \quad W=0.78 \mathrm{~N}, \quad \mathrm{~m}=0.080 \mathrm{~kg} .
$$


Problems

$E(2)$. A 2.50-kg mass is hung from the ceiling by a long rope. It is pulled to the side by a horizontal force of $10.0 \mathrm{~N}$. Find the tension in the long rope and the angle it will make with the vertical.

$F(3)$. A uniform ladder $10.0 \mathrm{~m}$ long, with a mass of $20.0 \mathrm{~kg}$, rests against a smooth wall and on a very rough floor, with the base of the ladder $6.0 \mathrm{~m}$ from the wall. An $80-\mathrm{kg}$ man has climbed the ladder to $8.0 \mathrm{~m}$ along the ladder from the bottom. Find the horizontal force that the floor must supply to keep the ladder from slipping.

Solutions

$E(2)$. Draw a free-body diagram of the forces on the $2.50-\mathrm{kg}$ mass, apply the first condition of equilibrium to the forces, and solve for the desired quantities: $\mathrm{T}=26.0 \mathrm{~N}, \theta=22.0^{\circ}$.

$F(3)$. Draw a free-body diagram showing all forces on the ladder (Fig. 8). Note that "smooth wall" implies no friction, which implies that $F$ is perpendicular to the wall. Notice the general similarity of this diagram to the free-body diagram of Problem C (except for orientation, direction, and magnitude of forces) and solve in a similar fashion.

$$
\begin{aligned}
& \Sigma F_{y}=V-W-W_{2}=0 \text { (this equation is not necessary), } \\
& \Sigma F_{x}=H-F=0, \quad \Sigma \tau_{B}=10.0 F \sin \theta-5.0 W \cos \theta-(8.0)\left(W_{2}\right) \cos \theta=0
\end{aligned}
$$

The result is $H=540 \mathrm{~N}$.

Figure 8

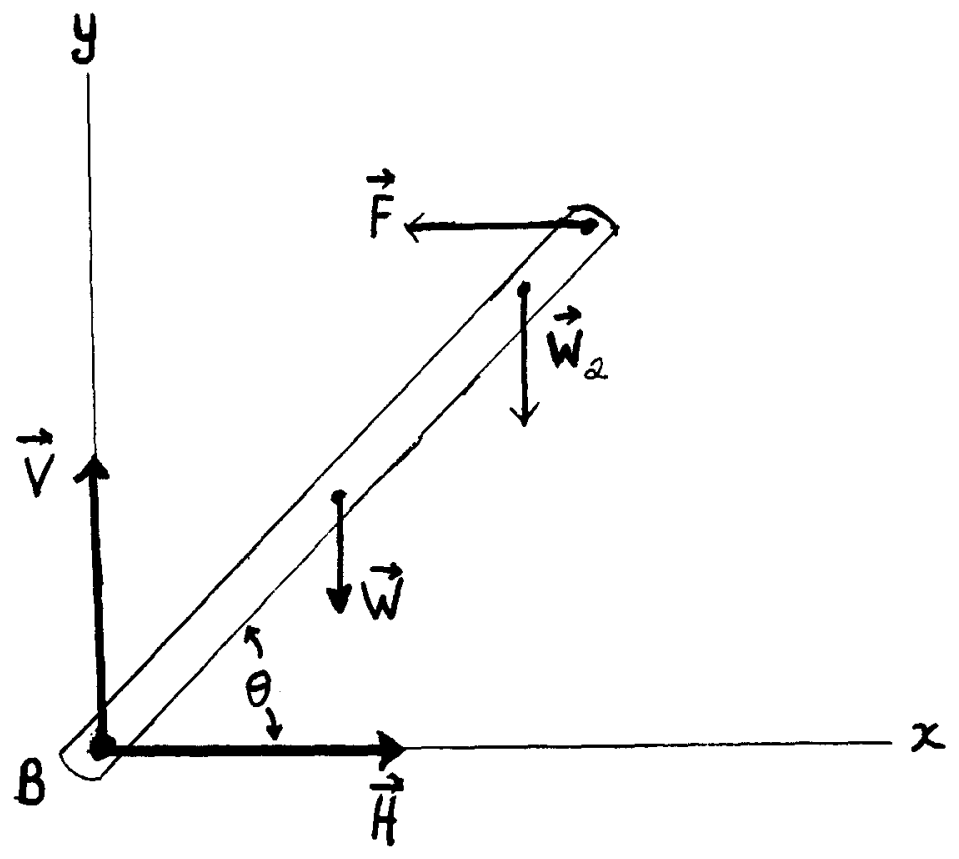




\section{PRACTICE TEST}

1. Describe how to find the center of gravity of an irregularly shaped planar object.

2. An object with a weight of $15.0 \mathrm{~N}$ is hung from two points as shown in Figure 9. Draw a free-body diagram and find the tension in the two ropes $A$ and $B$.

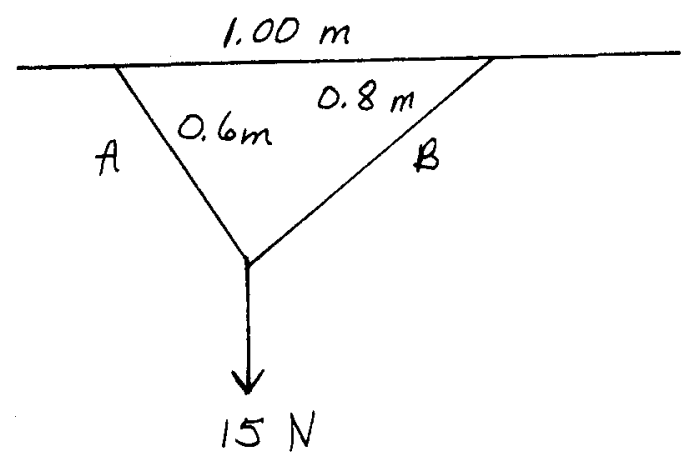

Figure 9

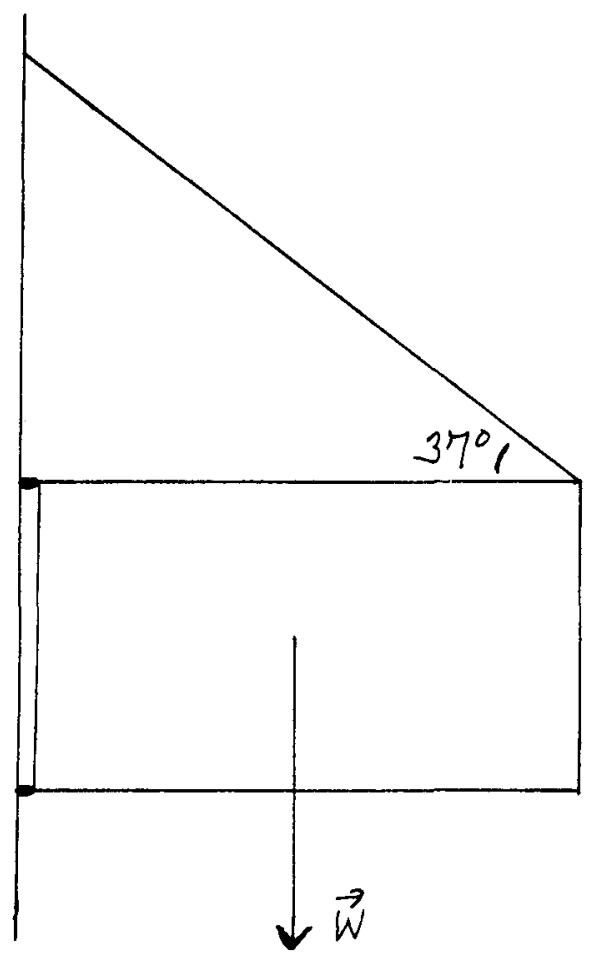

Figure 10

3. A uniform gate of weight $W$ is hung from two hinges as shown in Figure 10, but to relieve the strain on the hinges a guy wire is installed as shown and tightened until there is no horizontal force on the lower hinge. Draw a free-body diagram and find the horizontal force on the top hinge, in terms of $W$. 


\section{Practice Test Answers}

1. Assuming a plane object, suspend the object from a point on an edge and mark the vertical line (plumb line); then suspend the object from a different point and again mark the vertical line. The center of gravity is at the intersection of these lines.

2. Choose the point of application of the $15.0-\mathrm{N}$ force as the point in equilibrium and draw a free-body diagram (Fig. 11). Apply the first condition of equilibrium:

$$
\Sigma \mathrm{F}_{\mathrm{X}}=\mathrm{T}_{\mathrm{B}} \cos 37^{\circ}-\mathrm{T}_{\mathrm{A}} \cos 53^{\circ}=0, \quad \Sigma \mathrm{F}_{\mathrm{y}}=\mathrm{T}_{A} \sin 53^{\circ}+\mathrm{T}_{B} \sin 37^{\circ}-15=0 .
$$

Simultaneous solution of these equations gives us

$$
T_{B}=9.0 \mathrm{~N}, \quad T_{A}=12.0 \mathrm{~N} \text {. }
$$

3. Draw the free-body diagram as in Figure 12. Then

$$
\begin{aligned}
& \Sigma F_{X}=H-T \cos 37^{\circ}=0, \quad \Sigma F_{y}=V_{1}+V_{2}+T \sin 37^{\circ}-W=0, \\
& \Sigma \tau=0=L T \sin 37^{\circ}-W(L / 2)=0 \quad \text { (taking torques about the top hinge), } \\
& T=\frac{(1 / 2) W}{\sin 37^{\circ}}=0.83 \mathrm{~W} .
\end{aligned}
$$

From the first equation

$$
H=T \cos 37^{\circ}=0.83 \mathrm{~W} \cos 37^{\circ}=0.67 \mathrm{~W} \text {. }
$$
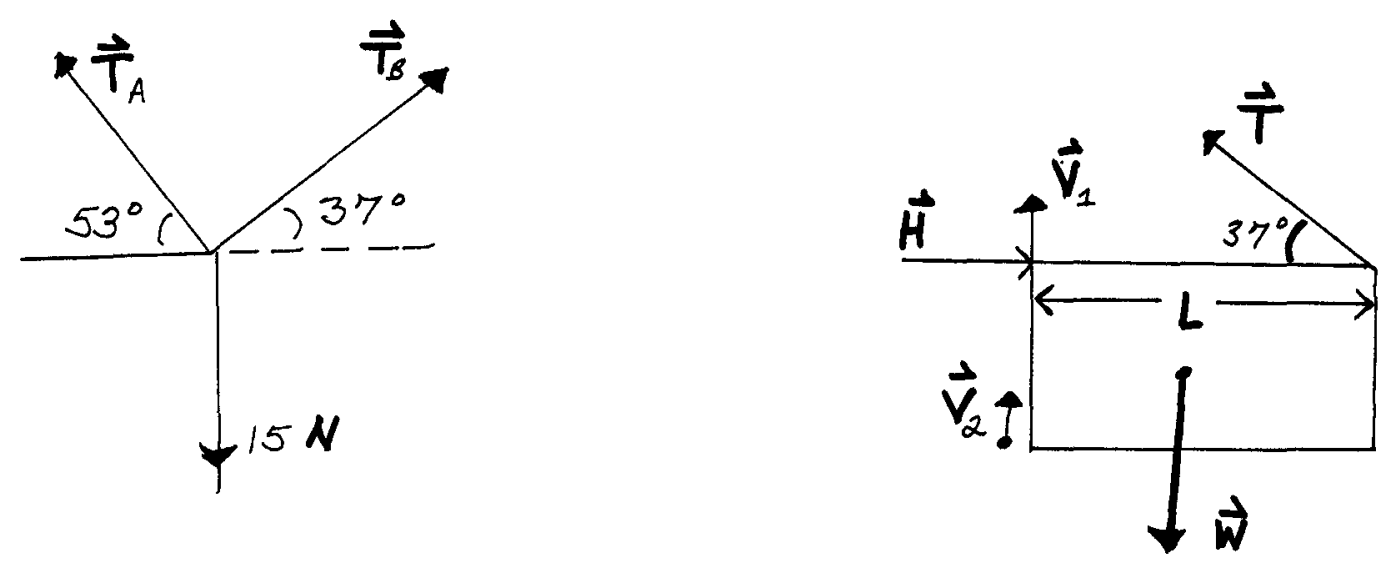

Figure 11

Figure 12 
Date

EQUILIBRIUM OF RIGID BODIES

Mastery Test Form A

$\begin{array}{lcc}\text { pass } & \text { recycle } \\ 1 & 2 & 3\end{array}$

Name Tutor

1. Describe what is meant by the "center of gravity" of an object.

2. A block of mass $6.0 \mathrm{~kg}$ is pulled up an incline at a constant velocity as shown in Figure 1. If the coefficient of sliding friction is 0.300 , how large a force $F$ is required?

3. A weight of $2.00 \times 10^{4} \mathrm{~N}$ is supported by a beam-and-guy-wire arrangement as shown in Figure 2. The beam is uniform and has a mass of $400 \mathrm{~kg}$. Draw a free-body diagram and find the vertical and horizontal components of the forces on the hinge at $A$.

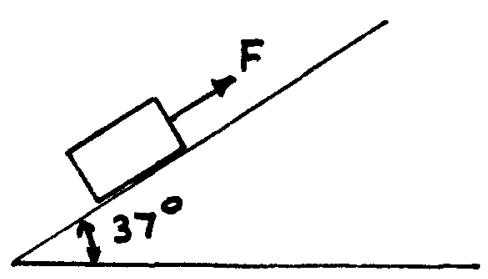

Figure 1

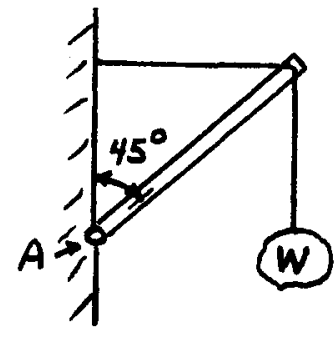

Figure 2 
Date

EQUILIBRIUM OF RIGID BODIES

Mastery Test Form B

$\begin{array}{lcc}\text { pass } & \text { recycle } \\ 1 & 2 & 3\end{array}$

Name

Tutor

1. State the first condition of equilibrium (translational) and describe how it differs from the second condition of equilibrium (rotational).

2. Two weights of $17.0 \mathrm{~N}$ each are suspended by cords $2.00 \mathrm{~m}$ long and attached to the ceiling at points $4.0 \mathrm{~m}$ apart. The weights are then connected with a cord that is $2.00 \mathrm{~m}$ long as shown in Figure 1. Draw a free-body diagram and find the tension in the connecting cord.

3. A playground seesaw, made from a plank $4.0 \mathrm{~m}$ long with a uniformly distributed mass of $50 \mathrm{~kg}$, is to be used by two children with masses $60 \mathrm{~kg}$ and $40 \mathrm{~kg}$. If the children are to sit at the ends of the plank, where should the fulcrum be placed for a balance?

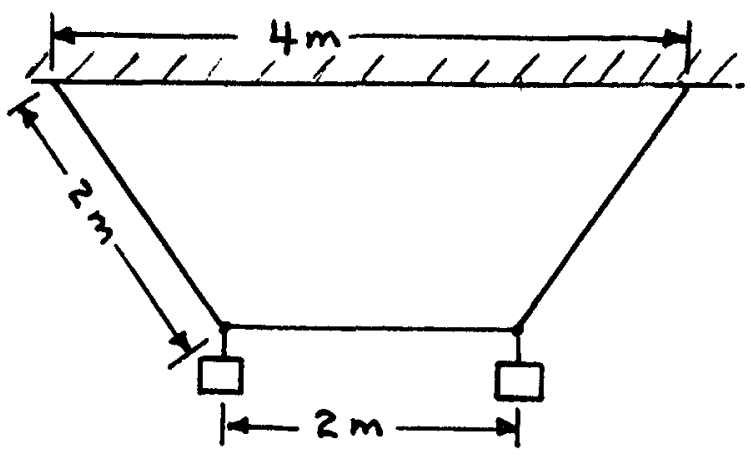

Figure 1 
Date

EQUILIBRIUM OF RIGID BODIES

Mastery Test Form C

$\begin{array}{lcc}\text { pass } & \text { recycte } \\ 1 & 2 & 3\end{array}$

Name

Tutor

1. State the second condition of equilibrium (rotational), and describe how it differs from the first condition of equilibrium (translational).

2. A rope of tensile strength $4500 \mathrm{~N}$ is tied to two sturdy posts $40 \mathrm{~m}$ apart. The rope is broken by applying a transverse force at the center. If the rope broke when the center was displaced by $1.00 \mathrm{~m}$, how large was the transverse force?

3. A nonuniform rod of length $L$ is attached to a wall by a hinge $A$ as shown in Figure 1. The lower end rests on a frictionless floor. The center of gravity is $(1 / 3) \mathrm{L}$ from the lower end. Draw a free-body diagram, and find the force on the hinge.

Figure 1

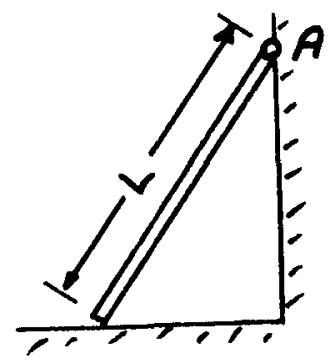


Instraotor

EQUILIBRIOA OF RIGID BODIES

Mastery Test Form D

Namo

1. Describe what is moant by the "conter of eravity" of an objeot.

2. The coefficient of static friction between the surface and
Block A, of weight $80 \mathrm{~N}$. is 0.40 . Find the maximum weight
of Block B which still keeps the system in equilibrium. The

2. The coefficient of static friction between the surface and
Block A, of weight $80 \mathrm{~N}$. is 0.40 . Find the maximum weight
of Block B which still keeps the system in equilibrium. The

2. The coefficient of static friction between the surface and
Block A, of weight $80 \mathrm{~N}$. is 0.40 . Find the maximum weight
of Block B which still keeps the system in equilibrium. The angle $\alpha$ is known. $\alpha=370$

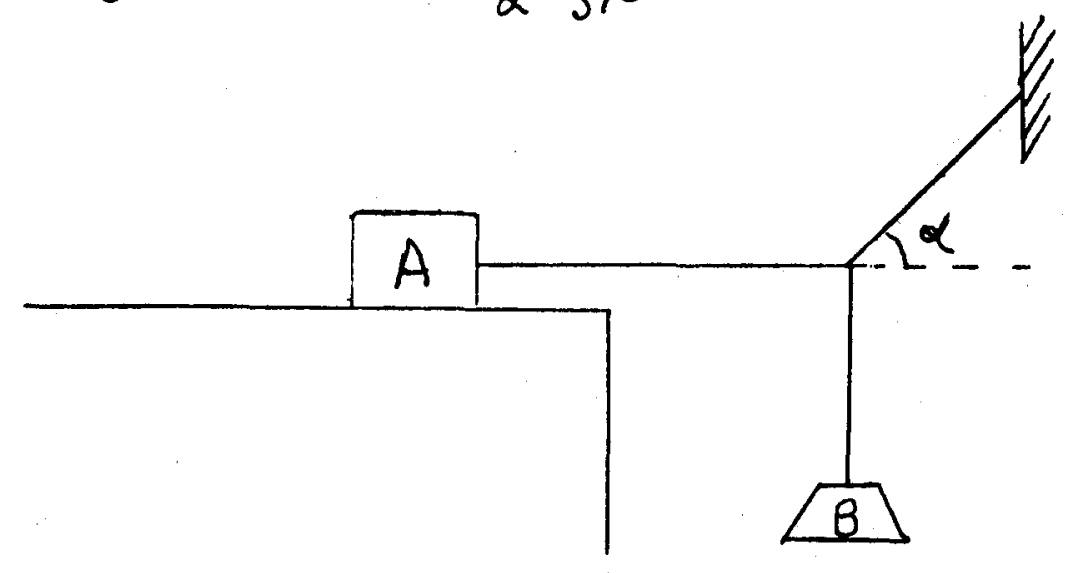

\section{Date}

PASS BDCICLS

$123 \quad 4 \quad 5$

Tutor A

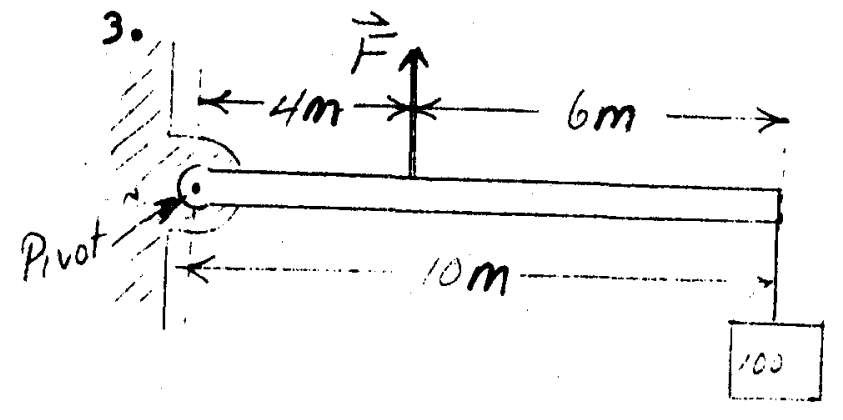

A $100 \mathrm{~N}$ weight hangs at the end of a $10 \mathrm{~m}$ rod which is free to rotate about the other end. Calculate the magnitude of the vertical force required to prevent rotation when the rod is horizontal.

Courtesy of University of Missouri-Rolla 
1. State the second condition of equilibrium and describe how it differa from the first condition of equilibrium.

2.

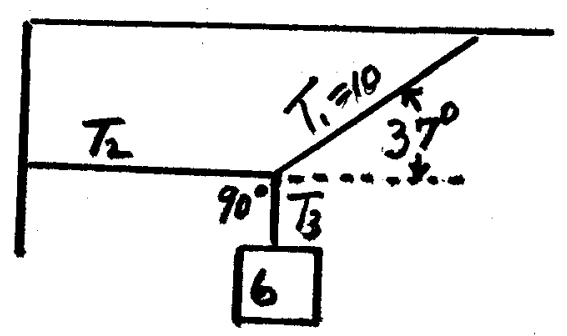

Calculate $T_{2}$ for the above system
A six Newton weight is supported as shown. Draw the free body vector diagram for the knot.

3. A horizontal bar 5 long and weighing $30 \mathrm{~N}$ is supported at its two ends. If the force supporting it at one end is $12 N$, find the distance of the center of gravity of the bar from that end. 
Instructor

EQUILIBRIUM OF RIGID BODIES

Mastery Tost Form F

Name

1. Describe what is meant by the "conter of erevity" of an objoet.

2.

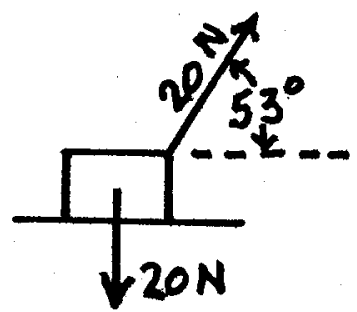

Calculate the normal force on the plane.
Date

PASS

RECYCLE

$\begin{array}{lllll}1 & 2 & 3 & 4 & 5\end{array}$

Tutor 
What To Look For

1. (a) Be sure the student has made the concise statement asked for in the question.

(b) Ask the student for the meaning of one or two key words in his answer.

2. (a) Check for a free-body diagram showing only directions and magnitudes of all external forces (not wrong, but explain to student).

(b) Check for a correct statement of $\Sigma F_{x}=0$ and $\Sigma F_{y}=0$.

(c) Be sure that he has obtained the correct answer, including magnitude, direction, and units.

3. (a) Check for a free-body diagram showing only directions, magnitudes, and points of application of all external forces.

(b) Check for a correct statement of $\Sigma F_{x}=0, \Sigma F_{y}=0$, and $\Sigma \tau=0$. (Be sure an explicit choice of axis has been made for calculation of torques.)

(c) Be sure student has obtained the requested answer, including magnitude, direction, and units.
Solutions

1. Center of gravity - That point about which the resultant of the gravitational torques on all the particles composing the rigid body is zero.

2. $49 \mathrm{~N}$ up the incline. 
What To Look For

1. (a) Be sure that the student has made the concise statement asked for in the question.

(b) Ask the student for the meaning of one or two key words in his answer.

2. (a) Check for a free-body diagram showing only directions and magnitudes of all external forces.

(b) Check for a correct statement of $F_{x}=0$ and $F_{y}=0$.

(c) Be sure that student has obtained the correct answer including magnitude, direction and units.

3. (a) Check for a free-body diagram showing only directions and magnitude, and points of application of all external forces (if missing, not wrong).

(b) Check for a correct statement of $\Sigma F_{x}=0 ; \Sigma F_{y}=0 ; \Sigma \tau=0$. (Be sure an explicit choice of axis has been made for calculation of torques.)

(c) Be sure that student has obtained the requested answer including magnitude, direction, and units.
Solutions

1. First condition of equilibrium (translationa 1) - The vector sum of the forces acting on the object equals zero, i.e., the object has a constant velocity.

2. $9.8 \mathrm{~N}$ along horizontal cord.

3. $1.70 \mathrm{~m}$ from the $60-\mathrm{kg}$ child. 
What To Look For

1. (a) Be sure that the student has made the concise statement asked for in the question.

(b) Ask the student for the meaning of one or two key words in his answer.

2. (a) Check for a free-body diagram showing only directions and magnitudes of external forces (not wrong if missing).

(b) Check for a correct statement of $\Sigma F_{x}=0$ and $\Sigma F_{y}=0$.

(c) Be sure that student has obtained the requested answer, including magnitude and units.

3. (a) Check for a free-body diagram showing only directions, magnitudes, and points of application of all external forces.

(b) Check for a correct statement of $\Sigma F_{x}=0 ; \Sigma F_{y}=0 ; \Sigma \tau=0$. (Be sure an explicit choice of axis has been made for calculation of torques.)

(c) Be sure that student has obtained the requested answer including magnitude, and direction.
Solutions

1. Second condition of equilibrium (rotationa 1) - The sum of the torques at a chosen pivot point equals zero, i.e., the object will not rotate.

2. $400 \mathrm{~N}$.
3. $\vec{F}=w / 3$ upwards with no horizontal component. 